\title{
CelluLAR AND MOLECULAR INTERACTIONS BETWEEN THE APICOMPLEXAN PARASITES PLASMODIUM AND THEILERIA AND THEIR HOST CELLS
}

\author{
HEUSSLER V.T.* \& STANWAY R.R.*
}

\section{Summary:}

Apicomplexan parasites of the genera Theileria and Plasmodium have complicated life cycles including infection of a vertebrate intermediate host and an arthropod definitive host. As the Plasmodium parasite progresses through its life cycle, it enters a number of different cell types, both in its mammalian and mosquito hosts. The fate of these cells varies greatly, as do the parasite and host molecules involved in parasite-host interactions. In mammals, Plasmodium parasites infect hepatocytes and erythrocytes whereas Theileria infects ruminant leukocytes and erythrocytes. Survival of Plasmodium-infected hepatocytes and Theileria-infected leukocytes depends on parasite-mediated inhibition of host cell apoptosis but only Theileria-infected cells exhibit a fully transformed phenotype. As the development of both parasites progresses towards the merozoite stage, the parasites no longer promote the survival of the host cell and the infected cell is finally destroyed to release merozoites. In this review we describe similarities and differences of parasite-host cell interactions in Plasmodium-infected hepatocytes and Theileria-infected leukocytes and compare the observed

phenotypes to other parasite stages interacting with host cells.

KEY WORDS : Plasmodium, Theileria, apoptosis, signal transduction, host cell transformation.

1 lasmodium liver stage parasites and Theileria schizonts are known to have profound effects on their host cells. Initially, both parasites inhibit the apoptotic machinery of the cells they infect (Heussler et al., 2002; Sturm et al., 2006). However, before merozoites are released to infect red blood cells, host cell death is initiated. In vitro, Plasmodium exoerythrocytic development lasts for only 3-5 days, depending on the Plasmodium species, whereas Theileriainfected leukocytes proliferate for an unlimited time in vitro during parasite schizogony. Only when merogony is induced by change in culture conditions or when the parasite is eliminated, is the transformed state of infected cells reversed and the host cell eventually ruptures to release merozoites (Swan et al., 2001).

Theileria-induced host cell proliferation results in a clonal expansion of the parasite population since parasites are equally distributed over both daughter cells

\footnotetext{
* Bernhard Nocht Institute for Tropical Medicine, Bernhard-NochtStr 74, 20359 Hamburg, Germany.

Correspondence: Volker Heussler

Tel.: ++49 4042818485 - Fax: ++49 4042818512 .

E-mail: heussler@bni-hamburg.de
}

(Dobbelaere \& Rottenberg, 2003). To realize this additional multiplication step, inhibition of host cell apoptosis is not sufficient and Theileria parasites go much further in their influence on the host cell by inducing a reversible host cell transformation, which provokes a leukemia-like phenotype in infected animals. Interestingly, Theileria parasites unlike Plasmodium parasites do not live in a parasitophorous vacuole, probably reflecting their close association with the internal environment of the host cell. Communication is certainly simplified by the parasite residing freely in the cytoplasm of the host cell. Although both Plasmodium liver stage parasites and Theileria schizonts interfere with signalling pathways of their host cells, the corresponding molecular mechanisms appear to be very different.

\section{THEILERIA}

7 heileria-infected leukocytes exhibit all signs of transformed cells (Fig. 1) and thus infected cells can easily be cultured in vitro. However, all these features disappear if the intracellular parasite is killed by the bupavarquone derivate BW720c (Dobbelaere \& Rottenberg, 2003). This drug specifically eliminates the parasite without affecting the host cell. BW720c-treated Theileria-infected cells stop proliferating, exhibit a resting phenotype and finally die by apoptosis, even after decades of in vitro culture, indicating that not genetic alteration, but epigenetic modifications (i.e. chromatin and DNA modification) are the basis of this parasite-induced phenotype. Generally, transformation of cells is genetically determined and thus considered as irreversible. Therefore, the entirely different Theileria-induced reversible transformation should be classified as "parasite-dependent reversible host cell transformation". Although it is still not clear how the presence of the parasite induces epigenetic changes, it is well established that the parasite interferes with host cell signalling pathways (Dobbelaere \& Kuenzi, 2004) suggesting that epigenetic alterations and parasite-dependent signalling are closely connec- 


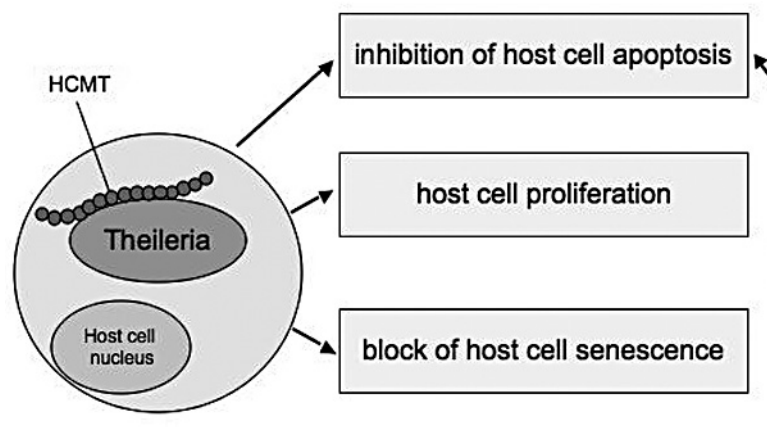

infected leukocyte

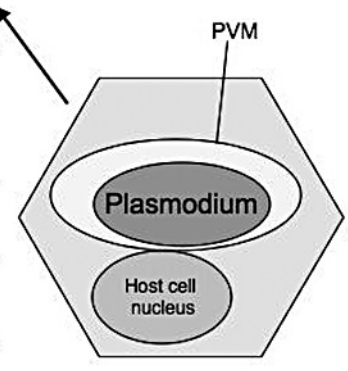

infected hepatocyte
Fig. 1. - Parasite-induced host cell modifications.

Theileria parasites reside freely in the host leukocyte and are interacting with host cell microtubules (HCMT). Theileria infection of leukocytes cause cell transformation including the depicted features. Plasmodium liver stage parasites live in a parasitophorous vacuole that is surrounded by a membrane (PVM). Infected cells are resistent to apoptotic stimuli. ted. In the following chapters, various aspects of parasite-induced reversible host cell transformation will be discussed.

\section{THEILERIA-INDUCED PROLIFERATION}

Upon stimulation, lymphocytes have the capacity to proliferate transiently before most of them die by activation induced cell death (AICD), a special form of apoptosis. Theileria-infected lymphocytes proliferate continuously and do not show signs of AICD. Since parasites are divided over both daughter cells, this proliferation results in vivo in a rapid clonal expansion of infected lymphocytes. These additional rounds of replication benefit the parasite and thus proliferation is one of the most important features of Theileriainfected cells. Proliferation is normally the result of growth factor receptor activation and the downstream PI3-kinase/PKB pathway. In all Theileria-infected leukocytes tested so far, a moderate but constitutive activation of the PI3K/PKB pathway was observed and its drug-mediated inactivation results in a reduced rate of proliferation of the parasitized cells (Baumgartner et al., 2000; Heussler et al., 2001). Interestingly, PI3K/PKB inhibition did not have an effect on the survival of the infected cells although it has been shown recently that in Theileria-infected cells, PKB is responsible for inhibiting the pro-apoptotic molecule Bad (Guergnon et al., 2006). Blocking of PKB activity is not lethal because Bad can also be inactivated by another kinase and only inhibition of both kinases results in apoptosis.

\section{INHIBITION OF HOST CELL APOPTOSIS}

If Theileria parasites actively block host cell apoptosis, drug-mediated elimination of the pathogen should result in host cell death. The theilericidal drug BW720c selectively eliminates the parasite within 2-3 days and, indeed, after five days of treatment, host cell apoptosis is induced. Interestingly, a clear correlation of apoptosis in BW720c-treated cells and DNA binding activity of the transcription factor NF- $\mathrm{kB}$ was described (Heussler et al., 1999). The constitutive activation of
NF- $\mathrm{KB}$ in Theileria-infected cells completely disappears after five days of treatment. Importantly, specific inhibitors that immediately block activation of NF- $\mathrm{KB}$, result in direct induction of apoptosis of the infected cells without affecting the parasite. Therefore, inhibition of host cell apoptosis in Theileria-infected cells depends, at least partly, on the host cell transcription factor NF- $\kappa \mathrm{B}$. Although a particular NF- $\kappa \mathrm{B}-$ inducing parasite factor has not yet been identified, the point at which the parasite interferes with the NF- $\mathrm{KB}$ cascade has been well characterised. NF- $\kappa B$ activation depends on phosphorylation and degradation of its associated inhibitor IkB. Responsible kinases belong to the IKK signalosome (IKK $\alpha, \beta, \gamma$ ) and it has been shown that this complex becomes activated by accumulation on the parasite surface (Fig. 3B) (Heussler et al., 2002). It is still not known how the parasite accumulates IKK signalosomes on its surface, but it is likely that the host cell cytoskeleton is involved since Theileria parasites are known to interact closely with host cell tubulin (Dobbelaere \& Rottenberg, 2003). Another question, which remains to be resolved, is whether accumulation is sufficient to activate the IKK signalosome or whether the parasite secretes an upstream kinase. An attractive hypothesis is that the parasite provides a scaffold protein for IKK kinases at its surface. IKK kinases are then arranged in a favourable position, resulting in IKB phosphorylation and NF- $\mathrm{KB}$ activation. Upon liberation from IKB, NF$\kappa \mathrm{B}$ translocates to the host cell nucleus and activates expression of several anti-apoptotic proteins (Kuenzi et al., 2003).

Transformation of cells often involves the expression of oncogenes and c-myc, one of the best-characterised oncogenes, was found to contribute to the transformed phenotype of Theileria-infected cells (Dessauge et al., 2005a). It has been suggested that the anti-apoptotic effects of c-myc in Theileria-infected cells, might be due to the c-myc-dependent expression of the Bcl-2 family member Mcl-1. Expression of c-myc in Theileriainfected lymphocytes depends on the presence of the parasite and ceases rapidly upon parasite elimination by BW720c (Dessauge et al., 2005b). The rapid decrease 
of c-myc levels upon BW720c treatment in comparison to the steady decrease in NF- $\mathrm{KB}$ activation over 3-5 days suggests a more central role of NF- $\mathrm{KB}$ in Theileriadependent inhibition of host cell apoptosis.

\section{Merozoite Development of TheILERIA}

Merogony of some Theileria strains can be induced by raising the temperature to $41^{\circ} \mathrm{C}$ (Shiels et al., 1992). Upon merozoite development, the host leukocyte gradually looses the transformed phenotype. On a molecular level it has been shown that IKK signalosomes disappear from the surface of the parasite and, as a consequence, NF- $\mathrm{KB}$ translocation to the host cell nucleus is blocked (Heussler et al., 2002). It is generally accepted that the host cell finally ruptures and releases merozoites but the molecular details of this event are not known and it might well be that merozoite liberation is a far more complicated process similar to what has been shown for Plasmodium merozoite release from hepatocytes (Sturm et al., 2006).

\section{INHIBITION OF CELL SENESCENCE}

When mammalian cells are normally cultured and serially passaged, it is found that cells cease dividing after 50 to 100 generations and enter what is called replicative senescence. In contrast, when Theileriainfected cells are cultured under the same conditions, they are capable of unlimited replication. It is now known that the crucial event limiting the life span of untransformed cells is the progressive erosion of chromosome ends. These ends are normally capped by repetitive, six base pair sequences called telomere repeats which, together, are approximately 6-12 kb long. In germ cells, which must retain their replicative capacity, and in certain stem cells, particularly of the haematopoietic system, an enzyme called telomerase helps to maintain normal telomere length. However, telomerase is not expressed in most somatic cells and the successive replicative cycles lead to the progressive shortening of telomeres. When a certain threshold is reached, p53 becomes activated, causing cell-cycle arrest and the phenomenon of replicative senescence. It is not surprising that many cancer cells reactivate telomerase expression or silence the expression of $\mathrm{p} 53$. Whether Theileria-infected cells express telomerase or are deficient in p53 activity has not yet been investigated. A number of Theileria-transformed cell lines have been cultured for several decades, undergoing thousands of cell divisions. The fact that $\mathrm{T}$ cells, once cured of the parasite, can continue to proliferate for up to three months in culture in the presence of IL-2 and potent mitogenic stimulation (Dobbelaere \& Rottenberg, 2003), is a strong indication that telomere length is maintained as long as the parasite is alive.
PARASITE MOLECULES THAT POTENTIALLY INTERFERE WITH HOST CELL SIGNALLING PATHWAYS

The fact that Theileria schizonts reside free in the cytoplasm of the host cell offers several possibilities as to how the parasite could interfere with host cell signalling cascades. An important prerequisite is that the parasite molecule is exposed to the host cell cytoplasm, presumably by presence on the parasite surface or by secretion from the parasite. Among the Theileria TashAT gene family, several members have been identified that are indeed secreted into the host cell cytoplasm and even translocate to the host cell nucleus (Shiels et al., 2004; Swan et al., 1999). TashAT2 and SuAT1 contain AT hook DNA-binding domains and it is notable that in higher eukaryotic cells, elevated levels of AT hook proteins are associated with oncogenic transformation. While expression of TashAT2 might be involved in downregulation of host cell responses to infection (Oura et al., 2006), SuAT1 expression is rather associated with the altered cellular morphology of Theileria-infected cells (Shiels et al., 2004) compared to resting leukocytes. The rather minor effects of heterologous expression of single parasite proteins in non-infected cell lines suggested that the transformed phenotype of infected cells is probably induced by many parasite factors rather than by a single dominant transforming parasite protein. Another secreted Theileria protein is TaSE, which appears to co-localize partly with host cell microtubules (Schneider et al., 2007). Theileria parasites are known to closely interact with host cell microtubules during mitosis, allowing passive distribution into both daughter cells and TaSE might be involved in connecting the parasite to host cell tubulin. Heterologous expression and subsequent experiments localising TaSE in uninfected cells confirmed the association with tubulin. Localisation of TaSE to the spindle poles and the midbody in Theileria-infected cells and in transfected cells suggested an interaction of the parasite protein with important regulators of mitosis like the Aurora A kinase (Schneider et al., 2007) and it will be a major challenge for the future to prove this hypothesis.

\section{THEILERIA STAGES IN THE DEFINITIVE HOST}

From the few experiments performed with Theileriainfected ticks, it can be concluded that upon infection, salivary gland cells undergo a massive hypertrophy and accumulate glycogen, which may serve as an energy source for the growing parasite (Blewett \& Branagan, 1973; Fawcett et al., 1982). However, since cell hypertrophy in the salivary gland has also been described after a non-infectious blood meal (Sauer et al., 1995) the role of the parasite in hypertrophic growth of salivary gland cells remains to be determined. More recently, cDNA libraries of $T$. parva-infected and uninfected salivary glands have been generated (Nene et al., 2004). Although no differences in abundantly expressed ESTs 
have been found, considerable variation of less abundant signalling molecules regulating the hypertrophic growth of salivary gland cells might exist. A detailed analysis of the transcriptome of parasitized salivary glands using cDNA arrays would certainly shed some light on which molecules are responsible for the hypertrophic growth of salivary gland cells during infection.

\section{PLASMODIUM}

\section{SPOROZOITE TRANSMIGRATION}

( $\mathrm{n}$ injection by an infected mosquito into a mammalian host, Plasmodium sporozoites travel with the bloodstream to the liver. Here sporozoites pass through Kupffer cells to reach hepatocytes (Pradel \& Frevert, 2001). Recently it was shown that sporozoites inhibit the defence mechanisms of the Kupffer cell that would normally lead to parasite destruction, by secretion of the sporozoite surface protein CSP (Usynin et al., 2007). On leaving the Kupffer cell, sporozoites traverse several hepatocytes (Fig. 2), which activates the parasite to secrete micronemal proteins necessary for invasion of a final hepatocyte (Mota et al., 2002). Activation of sporozoites is believed to occur by their contact with the intracellular environment of the hepatocyte and at least in part appears to be due to their exposure to intracellular concentrations of potassium (Kumar et al., 2007). To gain entry into a hepatocyte for traversal, sporozoites puncture the cell membrane using a perforin-like protein, spect2, or pplp1 (Ishino et al., 2005; Kadota et al., 2004). Sporozoite activation by cell traversal does not, however, appear to be essential, as genetically modified spect2-negative parasites, which were unable to traverse hepatocytes, can successfully infect hepatocytes in

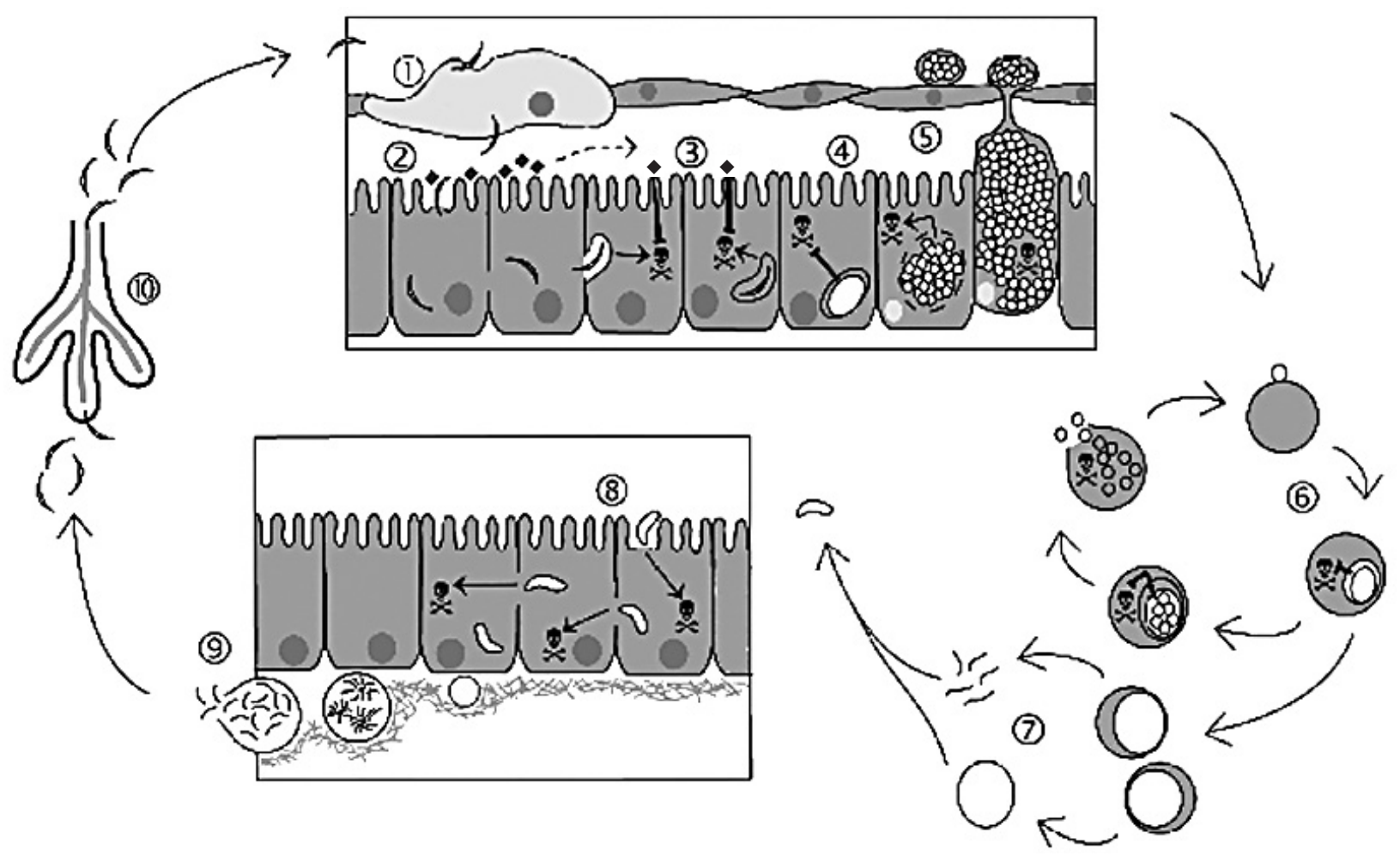

Fig. 2. - A generalised Plasmodium life cycle, highlighting host cell responses to traversal and infection by parasites. Cell death is depicted by $\dot{\gtrless}$, and the activation and suppression of host cell death are indicated by $\rightarrow$ and $\longrightarrow$ respectively. 1) Sporozoites, on injection into the vertebrate host by the mosquito, travel to the liver. To leave the blood vessel, they pass through Kupffer cells, suppressing the defensive respiratory burst of the traversed cell. 2) Sporozoites transmigrate through hepatocytes, entering and exiting by membrane perforation, but in most cases without causing hepatocyte death. 3) Once activated for invasion, sporozoites enter a final hepatocyte and reside within a parasitophorous vacuole. Apoptosis of these cells is initially inhibited by binding of the hepatocyte growth factor HGF ( $\bullet$ ) released by traversed cells) to the surface receptor c-MET, Y. 4) As parasite development continues, prevention of host cell apoptosis is directly mediated by the parasite. 5) At the completion of schizogony, the parasitophorous vacuole breaks down, releasing merozoites into the cytoplasm and the parasite triggers a novel form of host cell death. The result is the budding of merozoite-filled sacs into the liver sinusoid, which eventually rupture to release merozoites. 6) Merozoites invade red blood cells and undergo repeated cycles of asexual reproduction, during which host cell death is prevented by the parasite. 7) Some parasites develop into male or female gametocytes and on uptake into the mosquito during blood feeding, these gametocytes are activated. The released gametes fuse to form a zygote that quickly differentiates to a motile ookinete. 8) Escaping from the mosquito midgut, ookinetes traverse several epithelial cells and these die by apoptosis as a result. 9) On leaving the final epithelial cell, the ookinete differentiates into an oocyst and here thousands of sporozoites are produced. 10) Sporozoites travel to the salivary glands and here traverse cells to reach the salivary ducts, from where they are injected into a vertebrate host. 

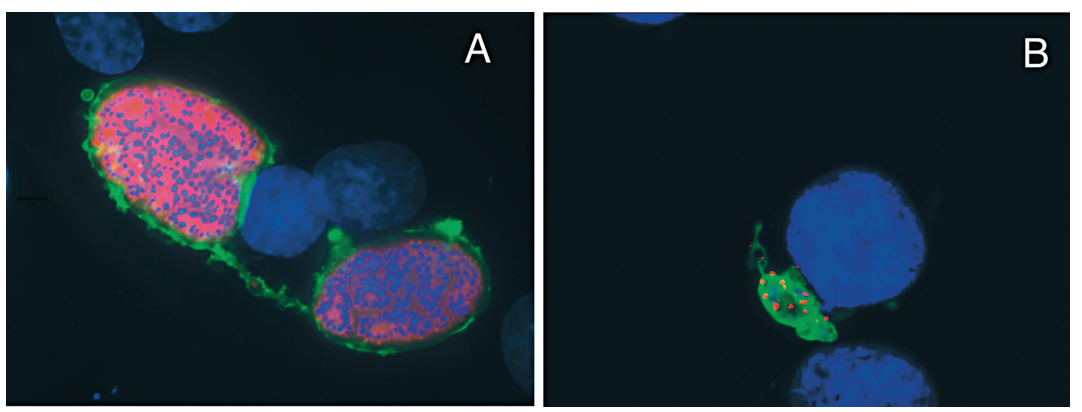

Fig. 3. - A) P. berghei-infected hepatic cell line. HepG2 cells were infected with $P$. berghei sporozoites and cultured for 48 hours. Cells were fixed and stained with anti-Exp1 antiserum, which stains the PVM and an antiserum that stains the parasite cytosol. B) T. parva-infected $\mathrm{T}$ cell. Infected cells grown in suspension were fixed on a slide and stained with an anti-Pim mAb, which stains the parasite membrane and an antiserum that labels host cell signalosomes localized on the surface of the parasite.

Kupffer cell-depleted mice. Although parasite transmigration seriously damages the target hepatocytes, most traversed cells survive (Mota et al., 2001) and can then present CSP secreted by traversing sporozoites via MHC class I molecules (Bongfen et al., 2007). Studies have shown that on exposure to sub-lytic concentrations of perforin, cells are able to re-seal their plasma membranes by the fusion of internal vesicular compartments to the damaged membrane, a process triggered by influx of $\mathrm{Ca}^{2+}$ ions upon membrane damage (Keefe et al., 2005). It is likely that traversed hepatocytes employ such a method of membrane repair following sporozoite entry and exit.

\section{PARASITE DEVELOPMENT WITHIN HEPATOCYTES AND INHIBITION OF APOPTOSIS}

On hepatocyte invasion and during subsequent schizont development within the parasitophorous vacuole (Fig. 3A), the parasite requires the host cell to stay alive and therefore host cell death must be prevented. Additionally to the role in sporozoite activation, traversed hepatocytes also are involved in inhibiting apoptosis of finally infected cells. Hepatocytes wounded by sporozoite traversal release hepatocyte growth factor (Carrolo et al., 2003), which activates the c-MET receptor on the surface of infected hepatocytes, leading to an inhibition of host cell apoptosis via a PI3 kinase-dependent pathway (Leiriao et al., 2005a). The HGF-dependent block of hepatocyte apoptosis during and immediately following sporozoite invasion is thought to be short-lived and resistance to apoptosis then becomes HGF and PI3 kinase-independent (van de Sand et al., 2005). The parasite itself then appears to be directly responsible for inhibition of apoptosis, as although hepatocytes infected with irradiated sporozoites are initially resistant to apoptosis, upon drug-mediated elimination of these parasites, host cells apoptose (Leiriao et al., 2005b). The molecular mechanism of how Plasmodium parasites interfere directly with the apoptotic machinery of the host cell remains to be elucidated but it is likely that the parasite secretes molecules into the host cell cytoplasm to regulate cell survival. Bano et al (2007) have observed that the parasite appears to interact with the host cell endoplasmic reticulum but the significance of this interaction for regulating host cell survival and the parasite and host molecules involved are not yet known.

Inhibition of apoptosis as a response to Plasmodium infection is also seen in erythrocytes containing $P$. berghei parasites. Here infected cells show a resistance to factors that would normally stimulate erythrocyte apoptosis, or eryptosis (Sobolewski et al., 2005). Again the mechanisms of this inhibition are not yet known.

\section{MEROZOITE DEVELOPMENT AND HOST CELL DEATH}

At late liver stages, upon completion of schizogony, a novel form of host cell death is triggered, that displays some hallmarks of apoptosis, but also marked differences, such as the failure of the infected hepatocyte to activate caspases and to display phosphatidylserine (PS) on its surface of the host cell (Sturm et al., 2006; Sturm \& Heussler, 2007). After the parasitophorous vacuole membrane (PVM) is broken down, merozoites are released into the host cell cytoplasm (Meis et al., 1985). Subsequently, merozoite-filled vesicles (merosomes) bud from the dying host cell and are released into the liver sinusoids, ensuring the safe passage of parasites into the blood stream (Sturm et al., 2006). PVM destruction, host cell death and merosome formation are initiated by yet unknown cysteine proteases. Although the proteolytic activity results in mitochondria damage and $\mathrm{Ca}^{2+}$ release, $\mathrm{Ca}^{2+}$-dependent activation of host cell scramblase and subsequent switch of PS residues to the outer leaflet of the host cell membrane does not occur. It has been shown that intracellular merozoites accumulate $\mathrm{Ca}^{2+}$ from the host cell cytoplasm and thus inhibit scramblase activation and PS switch. This way the parasite prevents the attack of macrophages, which would recognize and phagocytose PS-positive dying cells.

\section{SEARCHING FOR PARASITE MOLECULES}

WHICH INTERFERE WITH HOST SIGNALLING PATHWAYS

The Plasmodium parasite within the red blood cell is known to secrete proteins into the host cell cytoplasm and onto the host cell plasma membrane. These proteins have a profound effect on the morphology of the red blood cell and assist in parasite survival. A signal motif (commonly known as the PEXEL - Plasmodium export 
element - motif) has been found in many proteins secreted from the $P$. falciparum parasite into the host erythrocyte (Hiller et al., 2004; Marti et al., 2005) and this has allowed a secretome to be predicted for intra-erythrocytic Plasmodium parasites. Whether this secretome is also operating in liver stage parasites to deliver proteins that interfere with pathways leading to apoptosis, is an important goal for future research. Thus far, the only parasite protein identified as having a role in host cell manipulation during the liver stage is CSP, which has been shown to transiently block mRNA translation in infected and non-infected hepatocytes (Frevert et al., 1998).

\section{Plasmodium STAges IN THE Definitive host}

Contrasting to the primarily intracellular nature of the Plasmodium parasite within the mammalian host, within the mosquito the parasite is predominantly extracellular. Thus it does not need to manipulate host cell survival for the purpose of intracellular development. The parasite must, however, pass through mosquito cells, to escape from the mosquito midgut and later to enter the salivary ducts (Fig. 2). In exiting the midgut, the ookinete traverses a number of midgut epithelial cells before reaching the basal lamina and rounding up to become an oocyst (Zieler \& Dvorak, 2000). The process of cell transmigration is similar to that displayed by sporozoites in traversing hepatocytes, again requiring the action of perforin-like proteins (Ecker et al., 2007; Ishino et al., 2005; Kadota et al., 2004). In both processes, a prerequisite of parasite transmigration is secretion of the parasite protein CelTOS into the cytoplasm of the traversed cell (Kariu et al., 2006). Epithelial cells traversed by ookinetes invariably die by apoptosis and are extruded into the mosquito midgut (Han et al., 2000). It may be that the damage caused by entry of the ookinete, a much broader cell than the sporozoite, cannot be overcome by membrane repair, leading to cell death by apoptosis. Why ookinetes induce this slow form of cell death in epithelial cells and not a rapid death by necrosis is not clear, but it might be fatal for the mosquito if transmigration of hundreds of ookinetes results in rapid death of thousands of midgut epithelial cells resulting in a perforation of the midgut. However, as with sporozoites, ookinete traversal is not essential for further development of the parasite as ookinetes injected into the mosquito haemocoel are able to continue with normal sporogonic development.

\section{CONCLUDING REMARKS}

\footnotetext{
A lthough the phenotypes of Theileria-infected leukocytes and Plasmodium-infected hepatocytes have been reasonably well characterized,
}

the parasite-derived molecules triggering inhibition of apoptosis in both cases and cell transformation in case of Theileria infection, have still not been clearly defined. Sequencing of the genomes of several Plasmodium and Theileria species (Carlton et al., 2002; Gardner et al., 2002; Pain et al., 2005) will certainly help to identify putatively secreted parasite proteins that are highly interesting candidates for further analysis, but it should also be considered that the parasite has other possible methods of affecting signalling in the host cell. $\mathrm{Ca}^{2+}$ accumulation by Plasmodium merozoites and inhibition of PS exposure is a good example in this respect (Sturm \& Heussler, 2007). The most important goal in the future will be to use all the accumulated bioinformatic information and characterize the function of the identified parasite molecules in detail. Clearly, a lot of bench work is needed to complete the picture of parasite-dependent signalling in Theileria-infected leukocytes and Plasmodium-infected hepatocytes and it is safe to predict that we can expect exciting discoveries in these fields in the next few years.

\section{REFERENCES}

Bano N., Romano J.D., Jayabalasingham B. \& Coppens I. Cellular interactions of Plasmodium liver stage with its host mammalian cell. Int. J. Parasitol., 2007, 37, 1329-1341.

Baumgartner M., Chaussepied M., Moreau M.F., Werling D., Davis W.C., Garcia A. \& Langsley G. Constitutive PI3-K activity is essential for proliferation, but not survival, of Theileria parva-transformed B cells. Cell. Microbiol., 2000, 2, 329-339.

BlewetT D.A. \& Branagan D. The demonstration of Theileria parva infection in intact Rhipicephalus appendiculatus salivary glands. Tropical Animal Health Production, 1973, 5, 27-34.

Bongfen S.E., Torgler R., Romero J.F., Renia L. \& Corradin G. Plasmodium berghei-infected primary hepatocytes process and present the circumsporozoite protein to specific $\mathrm{CD}^{+} \mathrm{T}$ cells in vitro. J. Immunol., 2007, 178, 7054-7063.

Carlton J.M., Angiuoli S.V., Suh B.B., Kooij T.W., Pertea M., Silva J.C., Ermolaeva M.D., Allen J.E., Selengut J.D., Koo H.L., Peterson J.D., Pop M., Kosack D.S., Shumway M.F., Bidwell S.L., Shallom S.J., van AKen S.E., Riedmuller S.B., Feldblyum T.V., Cho J.K., Quackenbush, J., Sedegah M., Shoaibi A., Cummings L.M., Florens L., Yates J.R., Raine J.D., Sinden R.E., Harris M.A., Cunningham D.A., Preiser P.R., Bergman L.W., Vaidya A.B., van Lin L.H., Janse C.J., Waters A.P., Smith H.O., White O.R., Salzberg S.L., Venter J.C., Fraser C.M., Hoffman S.L., Gardner M.J. \& Carucci D.J. Genome sequence and comparative analysis of the model rodent malaria parasite Plasmodium yoelii yoelii. Nature, 2002, 419, 512-519.

Carrolo M., Giordano S., Cabrita-Santos L., Corso S., Vigario A.M., Silva S., Leiriao P., Carapau D., Armas-Portela R., Comoglio P.M., Rodriguez A. \& Mota M.M. Hepatocyte 
growth factor and its receptor are required for malaria infection. Nat. Med., 2003, 9, 1363-1369.

Dessauge F., Hilaly S., Baumgartner M., Blumen B., Werling D. \& LANGSLEY G. C-Myc activation by Theileria parasites promotes survival of infected B-lymphocytes. Oncogene, 2005a, 24, 1075-1083

Dessauge F., Lizundia R., Baumgartner M., Chaussepied M. \& Langsley G. Taking the Myc is bad for Theileria. Trends Parasitol., 2005b, 21, 377-385.

Dobbelaere D.A. \& RotTenberg S. Theileria-induced leukocyte transformation. Curr. Opin. Microbiol., 2003, 6, 377-382.

Dobbelaere D.A. \& Kuenzi P. The strategies of the Theileria parasite: a new twist in host-pathogen interactions. Curr. Opin. Immunol., 2004, 16, 524-530.

Ecker A., Pinto S.B., Baker K.W., Kafatos F.C. \& Sinden R.E. Plasmodium berghei: plasmodium perforin-like protein 5 is required for mosquito midgut invasion in Anopheles stephensi. Exp. Parasitol., 2007, 116, 504-508.

Fawcett D.W., Buscher G. \& Doxsey S. Salivary gland of the tick vector of East Coast fever. III. The ultrastructure of sporogony in Theileria parva. Tissue Cell, 1982, 14, 183-206.

Frevert U., Galinski M.R., Hugel F.U., Allon N., Schreier H., Smulevitch S., Shakibaei M. \& Clavijo P. Malaria circumsporozoite protein inhibits protein synthesis in mammalian cells. Embo J., 1998, 17, 3816-3826.

Gardner M.J., Hall N., Fung E., White O., Berriman M., Hyman R.W., Carlton J.M., Pain A., Nelson K.E., Bowman S., Paulsen I.T., James K., Eisen J.A., Rutherford K., SalzberG S.l., Craig A., Kyes S., Chan M.S., Nene V., Shallom S.J., Suh B., Peterson J., Angiuoli S., Pertea M., Allen J., Selengut J., Haft D., Mather M.W., Vaidya A.B., Martin D.M., Fairlamb A.H., Fraunholz M.J., Roos D.S., Ralph S.A., McFadden G.I., Cummings L.M., Subramanian G.M., Mungall C., Venter J.C., Carucci D.J., Hoffman S.L., Newbold C., Davis R.W., Fraser C.M. \& Barrell B. Genome sequence of the human malaria parasite Plasmodium falciparum. Nature, 2002, 419, 498-511.

Guergnon J., Dessauge F., Traincard F., Cayla X., Rebollo A., Bost P.E., LAngsley G. \& Garcia A. A PKA survival pathway inhibited by DPT-PKI, a new specific cell permeable PKA inhibitor, is induced by T. annulata in parasitized B-lymphocytes. Apoptosis, 2006, 11, 1263-1273.

Han Y.S., Thompson J., Kafatos F.C. \& Barillas-Mury C. Molecular interactions between Anopheles stephensi midgut cells and Plasmodium berghei: the time bomb theory of ookinete invasion of mosquitoes. Embo J., 2000, 19, 60306040 .

Heussler V.T., Machado J. Jr., Fernandez P.C., Botteron C., Chen C.G., Pearse M.J. \& Dobbelaere D.A. The intracellular parasite Theileria parva protects infected T cells from apoptosis. Proc. Natl. Acad. Sci. USA, 1999, 96, 7312-7317.

Heussler V.T., Kuenzi P., Fraga F., Schwab R.A., Hemmings B.A. \& Dobbelaere D.A. The Akt/PKB pathway is constitutively activated in Theileria-transformed leucocytes, but does not directly control constitutive NF-kappaB activation. Cell. Microbiol., 2001, 3, 537-550.

Heussler V.T., Rottenberg S., Schwab R., Kuenzi P., FernandeZ P.C., McKellar S., Shiels B., Chen Z.J., Orth K., Wal-
LaCH D. \& Dobbelaere D.A. Hijacking of host cell IKK signalosomes by the transforming parasite Theileria. Science, 2002, 298, 1033-1036.

Hiller N.L., Bhattacharjee S., van Ooij C., Liolios K., HarRison T., Lopez-Estrano C. \& Haldar K. A host-targeting signal in virulence proteins reveals a secretome in malarial infection. Science, 2004, 306, 1934-1937.

Ishino T., Chinzei Y. \& Yuda M. A Plasmodium sporozoite protein with a membrane attack complex domain is required for breaching the liver sinusoidal cell layer prior to hepatocyte infection. Cell. Microbiol., 2005, 7, 199-208.

Kadota K., Ishino T., Matsuyama T., Chinzei Y. \& Yuda M. Essential role of membrane-attack protein in malarial transmission to mosquito host. Proc. Natl. Acad. Sci. USA, 2004, 101, 16310-16315.

Kariu T., Ishino T., Yano K., Chinzei Y. \& Yuda M. CelTOS, a novel malarial protein that mediates transmission to mosquito and vertebrate hosts. Mol. Microbiol., 2006, 59, 13691379 .

Keefe D., Shi L., Feske S., Massol R., Navarro F., Kirchhausen T. \& Lieberman J. Perforin triggers a plasma membrane-repair response that facilitates CTL induction of apoptosis. Immunity, 2005, 23, 249-262.

Kuenzi P., Schneider P. \& Dobbelaere D.A. Theileria parvatransformed $\mathrm{T}$ cells show enhanced resistance to Fas/Fas ligand-induced apoptosis. J. Immunol., 2003, 171, 12241231.

Kumar K.A., Garcia C.R., Chandran V.R., Van Rooijen N., Zhou Y., Winzeler, E. \& Nussenzweig V. Exposure of Plasmodium sporozoites to the intracellular concentration of potassium enhances infectivity and reduces cell passage activity. Mol. Biochem. Parasitol., 2007, 156, 32-40.

Leiriao P., Albuquerque S.S., Corso S., van Gemert G.J., Sauerwein R.W., Rodriguez A., Giordano S. \& Mota M.M. HGF/MET signalling protects Plasmodium-infected host cells from apoptosis. Cell. Microbiol., 2005a, 7, 603-609.

Leiriao P., Mota M.M. \& Rodriguez A. Apoptotic Plasmodiuminfected hepatocytes provide antigens to liver dendritic cells. J. Infect. Dis., 2005b, 191, 1576-1581.

Marti M., Baum J., Rug M., Tille, L. \& Cowman A.F. Signalmediated export of proteins from the malaria parasite to the host erythrocyte. J. Cell. Biol., 2005, 171, 587-592.

Meis J.F., Verhave J.P., Jap P.H. \& Meuwissen J.H. Fine structure of exoerythrocytic merozoite formation of Plasmodium berghei in rat liver. J. Protozool., 1985, 32, 694-699.

Mota M.M., Pradel G., Vanderberg J.P., Hafalla J.C., Frevert U., Nussenzweig R.S., Nussenzweig V. \& Rodriguez A. Migration of Plasmodium sporozoites through cells before infection. Science, 2001, 291, 141-144.

Mota M.M., Hafalla J.C. \& Rodriguez A. Migration through host cells activates Plasmodium sporozoites for infection. Nat. Med., 2002, 8, 1318-1322.

Nene V., Lee D., Kang'a S., Skilton R., Shah T., De Villiers E., Mwaura S., Taylor D., Quackenbush J. \& Bishop R. Genes transcribed in the salivary glands of female Rhipicephalus appendiculatus ticks infected with Theileria parva. Insect. Biochem. Mol. Biol., 2004, 34, 1117-1128. 
Oura C.A., McKellar S., Swan D.G., Okan E. \& Shiels B.R. Infection of bovine cells by the protozoan parasite Theileria annulata modulates expression of the ISGylation system. Cell. Microbiol., 2006, 8, 276-288.

Pain A., Renauld H., Berriman M., Murphy L., Yeats C.A., Weir W., Kerhornou A., Aslett M., Bishop R., Bouchier C., Cochet M., Coulson R.M., Cronin A., De Villiers E.P., Fraser A., FosKer N., Gardner M., Goble A., Griffiths-Jones S., Harris D.E., Katzer F., Larke N., Lord A., Maser P., McKellar S., Mooney P., Morton F., Nene V., O’Neil S., Price C., Quail M.A., Rabbinowitsch E., Rawlings N.D., Rutter S., SAunders D., Seeger K., Shah T., Squares R., Squares S., Tivey A., Walker A.R., Woodward J., Dobbelaere D.A., Langsley G., Rajandream M.A., McKeever D., Shiels B., Tait A., Barrell B. \& Hall N. Genome of the host-cell transforming parasite Theileria annulata compared with T. parva. Science, 2005, 309, 131-133.

Pradel G.\& Frevert U. Malaria sporozoites actively enter and pass through rat Kupffer cells prior to hepatocyte invasion. Hepatology, 2001, 33, 1154-1165.

Sauer J.R., McSwain J.L., Bowman A.S. \& Essenberg R.C. Tick salivary gland physiology. Annu. Rev. Entomol., 1995, 40, $245-267$

Schneider I., Haller D., Kullmann B., Beyer D., Ahmed J.S. \& SEITZER U. Identification, molecular characterization and subcellular localization of a Theileria annulata parasite protein secreted into the host cell cytoplasm. Parasitol. Res., 2007, 101, 1471-1482.

Shiels B., Kinnaird J., McKellar S., Dickson J., Miled L.B., Melrose R., Brown D. \& TAIT A. Disruption of synchrony between parasite growth and host cell division is a determinant of differenciation to the merozoite in Theileria annulata. J. Cell. Sci., 1992, 101 (Pt 1), 99-107.

Shiels B.R., McKellar S., Katzer F., Lyons K., Kinnaird J., WARD C., WASTLING J.M. \& SWAN D. A Theileria annulata DNA binding protein localized to the host cell nucleus alters the phenotype of a bovine macrophage cell line. Eukaryot. Cell, 2004, 3, 495-505.

Sobolewski P., Gramaglia I., Frangos J.A., Intaglietta M. \& van der Heyde H. Plasmodium berghei resists killing by reactive oxygen species. Infect. Immun., 2005, 73, 67046710 .

Sturm A., Amino R., van de Sand C., Regen T., Retzlaff S., Rennenberg A., Krueger A., Pollok J.M., Menard R. \& HeusSLER V.T. Manipulation of host hepatocytes by the malaria parasite for delivery into liver sinusoids. Science, 2006, 313, 1287-1290.

STurm A. \& HeussLer V. Live and let die: manipulation of host hepatocytes by exoerythrocytic Plasmodium parasites. Med. Microbiol. Immunol., 2007, 196, 127-133.

Swan D.G., Phillips K., Tait A. \& Shiels B.R. Evidence for localisation of a Theileria parasite AT hook DNA-binding protein to the nucleus of immortalised bovine host cells. Mol. Biochem. Parasitol., 1999, 101, 117-129.

Swan D.G., Phillips K., McKellar S., Hamilton C. \& Shiels B.R. Temporal co-ordination of macroschizont and merozoite gene expression during stage differentiation of Theileria annulata. Mol. Biochem. Parasitol., 2001, 113, 233-239.
UsYNin I., KLOTZ C. \& FreverT U. Malaria circumsporozoite protein inhibits the respiratory burst in Kupffer cells. Cell. Microbiol., 2007, 9, 2610-2628.

van de Sand C., Horstmann S., Schmidt A., Sturm A., Bolte S., Krueger A., Lutgehetmann M., Pollok J.M., Libert C. \& Heussler V.T. The liver stage of Plasmodium berghei inhibits host cell apoptosis. Mol. Microbiol., 2005, 58, 731-742.

Zieler H. \& DvoraK J.A. Invasion in vitro of mosquito midgut cells by the malaria parasite proceeds by a conserved mechanism and results in death of the invaded midgut cells. Proc. Natl. Acad. Sci. USA, 2000, 97, 11516-11521. 